\title{
NORMAS GERAIS PARA PUBLICAÇÃO NA REVISTA PRÁXIS EDUCACIONAL
}

A Revista Práxis Educacional é um periódico trimestral do Programa de Pós-Graduação em Educação (PPGEd), da Universidade Estadual do Sudoeste da Bahia (Uesb). Publica artigos inéditos resultantes de pesquisas científicas, além de resenhas de livros. Seu objetivo central é divulgar pesquisas e estudos vinculados ao campo da educação, desenvolvidos por pesquisadores de diferentes contextos educacionais do Brasil e do exterior.

\section{INSTRUÇÕES GERAIS PARA PUBLICAÇÃO}

1.1 Serão publicados trabalhos inéditos, resultantes de pesquisa científica, relacionados com a área de educação, apresentados conforme normas da Associação Brasileira de Normas Técnicas (ABNT) em vigor: NBR 6022 - Artigo em publicação periódica impressa; NBR 6023 - Referências; NBR 10520 Citações em documentos.

1.2 Serão aceitos, para análise com vistas à publicação, trabalhos de docentes, discentes de pós-graduação, pesquisadores de Instituições de Ensino Superior, bem como de outros espaços educativos (movimentos sociais, escolas, organizações não-governamentais, entre outros).

1.3 Junto com o texto, cada autor deverá encaminhar a autorização para publicação do trabalho, se aprovado pelo Comitê Científico e pelo Conselho Editorial. O modelo para a autorização se encontra no site da revista seguindo o caminho: Sobre > Política > Autorização para publicação de trabalhos.

1.4 Cada trabalho encaminhado (artigo científico, dossiê temático e resenha) será objeto de apreciação pelo Comitê Científico (avaliação entre pares), que decidirá pela aprovação ou não do trabalho.

1.5 Os autores serão informados, por e-mail, da aceitação ou não do trabalho para publicação.

1.6 Os trabalhos deverão ser encaminhados para o endereço eletrônico da revista (rpraxiseducacional@yahoo.com.br) em arquivo compatível com o padrão MS Word para Windows. Só será aceito um trabalho por arquivo.

1.8 As tabelas, quadros e gráficos, enumerados sequencialmente, deverão ser feitos em preto e branco, por meio de recursos do Word, de acordo com as normas em vigor.

1.9 Quanto à extensão dos trabalhos encaminhados, é necessário atender aos seguintes requisitos:

a) artigos científicos, entre 20 e 30 páginas, sem contar referências; 
b) resenhas, de 3 a 5 páginas;

1.10 Será garantido o anonimato de autores e pareceristas no processo de análise dos trabalhos apresentados.

1.11 Todos os artigos, dossiês temáticos e resenhas, enviados para a Revista Próxis Educacional, serão submetidos à apreciação do Conselho Editorial, que analisa sua adequação às Normas e à Política Editorial da Revista e decide por seu envio aos pareceristas ou sua recusa prévia.

1.12 Cabe ao Conselho Editorial da Revista decidir pela oportunidade e publicação dos trabalhos aprovados pelo Comitê Científico.

1.13 Para cada autor de artigo publicado, será destinado um exemplar da revista.

1.14 Os textos devem ser submetidos a uma revisão cuidadosa de linguagem antes de serem encaminhados para a revista.

1.15 Só serão encaminhados para o Comitê Científico os trabalhos que atenderem às normas de formatação e da Associação Brasileira de Normas Técnicas (ABNT). O trabalho que estiver fora das normas será enviado ao autor, para realizar os ajustes que se fizerem necessários e reencaminhar à revista.

1.15 A Revista Práxis Educacional reservar-se ao direito de não publicar artigos e resenhas de mesma autoria (ou coautoria) em intervalos inferiores a dois anos.

1.16 À Revista Práxis Educacional ficam reservados os direitos autorais no tocante a todos os artigos nela publicados.

1.17 A política de ética de publicação da Revista: i) obedece à Resolução no 196/1996, do Conselho Nacional de Saúde, que estabelece as normas regulamentadoras sobre pesquisas, envolvendo seres humanos; ii) procede ao envio para o (s) autor (es) do parecer conclusivo do artigo.

1.18 A apreciação do artigo pelos pareceristas reside na consistência do resumo (apresentando, necessariamente, objetivo, referencial teórico e/ou procedimento metodológico e resultados); consistência interna do trabalho (com relação ao objetivo, referencial teórico e/ou procedimento metodológico e aos resultados); consistência do título (com relação ao conhecimento produzido); qualidade do conhecimento educacional produzido (com relação à densidade analítica, evidências ou provas das afirmações apresentadas e ideias conclusivas); relevância científica (com relação aos padrões de uma pesquisa científica); originalidade do trabalho (com relação aos avanços da área de Educação) e adequação da escrita à norma culta da língua portuguesa. 
1.19 Se necessário, o artigo aprovado será submetido a pequenas correções, visando à melhoria do texto.

1.20 Cada artigo poderá ter no máximo três (3) autores, todos pertencentes a grupos de pesquisas. Exige-se que, pelo menos, um dos autores tenha o título de doutor. Quando justificado, o artigo poderá ter quatro (4) autores.

1.21 É exigido o título de doutor para o autor cujo artigo não teve a participação de outrem. Esse autor precisa, também, ser integrante de um grupo de pesquisa.

$1.22 \mathrm{O}(\mathrm{s})$ autor(es) deve $(\mathrm{m})$ apresentar uma declaração de que o artigo é, realmente, inédito.

\section{NORMAS PARA APRESENTAÇÃO DE TRABALHOS}

Serão aceitos trabalhos resultantes de estudos e pesquisas. A digitação, a organização e a formatação do texto devem seguir as seguintes orientações:

2.1 Os trabalhos devem ser digitados no editor de textos do Microsoft Word:

- papel tamanho A4 $(21 \mathrm{~cm} \times 29,7 \mathrm{~cm})$;

- Margem direita e inferior com $2 \mathrm{~cm}$;

- Margem esquerda e superior de $3 \mathrm{~cm}$;

- Espaçamento entre linhas: 1,5 cm;

- Letra Century Gothic, fonte 12, para o desenvolvimento do texto, excetuando-se as citações longas, que devem conter fonte 11 e as notas de rodapé que devem estar com fonte 10;

- Alinhamento justificado no texto, e à esquerda, nas referências.

2.2 Os trabalhos devem ser apresentados da seguinte forma:

2.2.1 Título - centralizado, em letras maiúsculas, fonte Century Gothic, tamanho 12, negrito. O título deverá conter, no máximo, 100 (cem) caracteres com espaço.

2.2.2 Nome do autor - abaixo do título, fonte Century Gothic, tamanho 12, afastado por um espaço $(1,5)$, em itálico, alinhado à direita.

2.2.3 A titulação do autor, instituição, cidade da instituição, órgão de lotação, e-mail, grupo de pesquisa a que pertence devem constar no final do texto, após as Referências.

2.2.3 Resumo em língua portuguesa - contendo no máximo 250 palavras, fonte Century Gothic, tamanho 11, em espaço simples, apresentado depois do nome do autor, afastado deste por um espaço $(1,5)$. 
2.2.4 Palavras-chave em língua portuguesa, em número de três, devem ser apresentadas logo após o resumo, afastadas por um espaço simples, em ordem alfabética e separadas por ponto. O termo Resumo fica na linha anterior ao resumo propriamente dito. O termo Palavras-chave deve estar em negrito e seguido por dois pontos. As palavras/termos chaves são separadas por ponto e somente a primeira letra das palavras chave é maiúscula.

2.2.5 As citações, as notas e as referências devem seguir as normas da ABNT em vigor. As notas de rodapé devem ser colocadas ao longo do texto. As citações devem estar de acordo com as normas recentes da ABNT, usando o sistema autor-data.

2.2.6 Resumo em inglês e em espanhol (Abstract e Resumen). Título do trabalho e versão do resumo em inglês e em espanhol, contendo no máximo 250 palavras, fonte Century Gothic, tamanho 11, em espaço simples, apresentados após o Resumo em língua portuguesa, afastado deste por um espaço $(1,5 \mathrm{~cm})$. Os termos Abstract e Resumen devem estar em negrito e seguidos por dois pontos.

2.2.7 Palavras-chave em inglês (Keywords) e em espanhol (Palabras clave). Versão das palavras-chave do resumo. Em número de três, devem ser apresentadas logo após o abstract, afastadas por um espaço simples, em ordem alfabética e separadas por ponto. Os termos Keywords e Palabras clave devem estar em negrito e seguidos por dois pontos.

2.2.8 As referências devem ser apresentadas ao final do texto, contendo exclusivamente as obras citadas. Alinhadas somente à margem esquerda do texto, em espaço simples e separadas entre si por espaço duplo.

2.2.6 Escrever o nome completo dos autores e dos tradutores (quando for o caso) nas Referências.

2.2.10 Os quadros, tabelas, gráficos, figuras (fotografias ou desenhos) devem vir ao longo do texto, o mais próximo possível dos parágrafos em que são mencionados. Os títulos devem estar acima e as fontes abaixo de cada um desses elementos.

2.2.11 Quando o texto contiver notas, estas devem ter o caráter unicamente explicativo. Cada nota explicativa deverá conter, no máximo, 400 (quatrocentos) caracteres.

2.2.12 A titulação do autor, instituição, cidade da instituição, órgão de lotação, e-mail, grupo de pesquisa a que pertence devem constar no final do texto, após as referências.

2.2.13 A resenha, de três a cinco páginas, deverá vir com um título em português, inglês e espanhol (negrito e caixa baixa) e a referência do livro resenhado. 
2.2.14 Cada resenha poderá ter no máximo dois (2) autores.

2.2.15 A apreciação da resenha reside na sua clareza informativa, crítica e crítico-informativa; apresentação do conhecimento produzido para área de Educação; consistência na exposição sintética do conhecimento do livro resenhado; adequação da escrita à norma culta da língua portuguesa e às Normas da Revista Práxis Educacional.

\section{EXEMPLOS DE CITAÇÕES}

\subsection{Citações indiretas:}

Para sua formação profissional, é imprescindível que o graduando, ao longo do curso, tenha contatos com as escolas da comunidade para conhecer o cotidiano escolar, suas necessidades, seus problemas e seus avanços (LIBÂNEO, 2004).

\subsection{Citações diretas, curtas (contendo até três linhas):}

Segundo Crusoé (2009, p. 99), "[...] na representação dos professores, a ideia de relação não se restringe somente aos conteúdos, mas também à relação entre os atores da prática social."

Pode-se concluir que, "[...] na representação dos professores, a ideia de relação não se restringe somente aos conteúdos, mas também à relação entre os atores da prática social." (CRUSOÉ, 2009, p. 99).

3.3 Citações diretas, com mais de três linhas - destacadas em fonte Century Gothic, tamanho 11, alinhadas com o texto à direita e com o recuo de $4 \mathrm{~cm}$ da margem esquerda.

[...] Constata-se que a educação da população resulta na viabilidade de (melhor) qualificação profissional, além de maior número de pessoas com formação para o trabalho - o que vai gerar mão de obra excedente e, por isso mesmo, a possibilidade real de redução de gastos com pagamento de pessoal, como manda a lei da oferta e da procura. (NUNES, 2010, p. 64).

\section{EXEMPLOS DE REFERÊNCIAS}




\subsection{Monografias (livros e trabalhos acadêmicos)}

CRUSOÉ, Nilma Margarida de Castro. Interdisciplinaridade: representações sociais de professores de Matemática. 1. ed. Natal: Edufrn, 2009.

TAVARES, Eleuza Diana Almeida. Currículo de história do ensino médio: a prática do professor. 157f. Dissertação (Mestrado em Educação).

Universidade Estadual do Sudoeste da Bahia, Vitória da Conquista, 2015. Orientadora: Prof ${ }^{a}$. Dra Maria Cristina Dantas Pina.

MOREIRA, Núbia Regina. O feminismo negro brasileiro: um estudo do movimento de mulheres negras no Rio de Janeiro e São Paulo. $275 f$. Dissertação (Mestrado em Sociologia). Universidade Estadual de Campinas, Unicamp, São Paulo, Campinas, 2007. Orientadora: Prof ${ }^{a}$. Dr ${ }^{a}$ Maria Lygia Quartim de Moraes.

\subsection{Monografias em meio eletrônico}

LEITE, Maria Iza Pinto de Amorim (Org.). Docência e pesquisa. Vitória da Conquista: Edivesb, 2007. 286p. ISBN 978-85-88505-61-2. CD-ROM.

\subsection{Partes de monografia}

MARTíNEZ, Albertina Mitjáns. Aprendizagem criativa: desafios para a prática pedagógica. In: NUNES, Claudio Pinto (Org.). Didática e formação de professores. ljuí: Unijuí, 2012. p. 93-124.

CRUSOÉ, Nilma Margarida de Castro; AMADO, João da Silva; RIBEIRO, Márcia Maria Gurgel. A prática interdisciplinar na escola e a formação continuada de professores. In: CRUSOÉ, Nilma Margarida de Castro; RIBEIRO, Márcia Gurgel; SILVA, Claudionor Alves da (Org.). Desafios educacionais no cotidiano escolar. 1. ed. ljuí: Unijuí, 2010, p.197-213.

\subsection{Publicação em periódicos}

CAIRES, Flávia Cristina Batista; SALES, Sheila Cristina Furtado. Panorama das produções científicas em políticas públicas de juventude: uma análise do Projovem Urbano. Práxis Educacional, Vitória da Conquista: Ediuesb, v.10, n. 17. p. 197-217, 2014. Disponível em: 
<http://periodicos.vesb.br/index.php/praxis/article/viewFile/4546/4345>.

Acesso em: 10 jun. 2015.

LIMA FILHO, Domingos Leite. Expansão da educação superior e da educação profissional no Brasil: tensões e perspectivas. Educação em

Questão, Natal, v. 51, n. 37, p. 195-223, jan./abr. 2015.

\subsection{Artigo/matéria em jornal}

WEBER, Demétrio. Verba do Fundef é desviada em 350 municípios. Estado de São Paulo, São Paulo, 28 jun. 2000. Disponível em: <http://www.Estadao.com.br>. Acesso em: 30 jun. 2000.

LEITE, Maria Iza Pinto de Amorim. Mini-curso: ensino e aprendizagem. Jornal Eventos e Promoções, Vitória da Conquista-BA, v. 40, p. 28-29, $1^{\circ}$ maio 1996.

\subsection{Trabalho apresentado em evento}

SOUZA, Ester Maria de Figueiredo; COELHO, Fernanda de Castro Batista. Aula de português: palavras e contra palavras. In: SIMPÓSIO INTERNACIONAL DE ENSINO DE LÍNGUA PORTUGUESA, 2012. Uberlândia. Anais do SIELP. v. 2. n.1. Uberlândia: $\quad 2012 . \quad$ Disponível em: <http://periodicos.uesb.br/index.php/praxis/article/viewFile/292/325>. Acesso em: 13 set. 2012.

NOGUEIRA, Eliara Cristina da Silva; NUNES, Cláudio Pinto. Financiamento da educação no Brasil: limites e possibilidades de cumprimento do piso salarial nacional. In: II ENCONTRO ESTADUAL DE POLÍTICA E ADMINISTRAÇÃO DA EDUCAÇÃO DA BAHIA, I SEMINÁRIO DE ESTUDOS PESQUISAS EM EDUCAÇÃO DE CAMAÇARI. Anais... Salvador: UFBA, 2016. p. 315-326.

SILVA, Claudionor Alves da. O ensino da leitura e da escrita: uma abordagem discursiva. In: SEMINÁRIO DE EDUCAÇÃO DE PESSOAS JOVENS E ADULTAS, 2; SEMINÁRIO DE POLÍTICAS PÚBLICAS, GESTÃO E PRÁXIS EDUCACIONAIS, 1, 2006, Vitória da Conquista/BA. Anais do II Epja e I Gepráxis: Políticas, gestão e práxis educacionais, Vitória da Conquista/BA: Uesb, 2006. p. 96-109.

\subsection{Autoria desconhecida}


PLENÁRIO conclui votação da PEC do Fundeb. CNTE Informa. Brasília, 7 dez. 2006, n 366. Disponível em: <http://www.cnte.org.br>. Acesso em: 9 dez. 2006.

\subsection{Legislação}

BRASIL. Congresso Nacional. Constituição. Emenda Constitucional n. 14/96, de 12 de setembro de 1996. Modifica os artigos 34, 208, 211 e 212 da Constituição Federal e dá nova redação ao Artigo 60 do Ato das Disposições Constitucionais Transitórias. MEC. Brasília, 1996. Disponível em: <http://www.mec.gov.br>. Acesso em: 23 ago. 2004. 